\title{
Why is research fraud wrong?
}

\author{
This article was published in the following Dove Press journal: \\ International Journal of General Medicine \\ 4 October 2013 \\ Number of times this article has been viewed
}

\section{SG Fraser}

Editor-in-Chief, Sunderland Eye Infirmary, Sunderland, UK
Correspondence: SG Fraser Sunderland Eye Infirmary, Queen Alexandra Rd, Sunderland, Tyne and Wear SR2 9HP, UK Email scott.fraser@dovepress.com
Why is research fraud wrong? The answer to this question may seem self-evident. However, a small minority of researchers can certainly justify research fraud in their own minds. Why do they do this and why does it matter?

To answer the first part of this question is difficult as there may be any number of reasons for committing scientific fraud:

\section{- Career progression}

Publication of papers is one of the most important markers of research activity. The 'better' the journal (ie, the higher the impact factor), the more the publication 'counts'. Generally speaking, journals prefer to publish interesting papers, ie, those that will get the most attention and citations. One really crucial paper can cement an entire research career, and the temptation to favorably alter results that are not quite statistically significant may be too great.

- Research grants

These are often awarded as much for the track record of the researcher as for the quality of the proposal. Research that seems to be producing results is much more likely to be awarded further funding than research which seems to be going nowhere. Retaining employment (for you or your team) may be dependent on attaining grants, leading to alterations in research results in order to ensure they are significant.

- Ease of fabrication

It can be quite easy to fabricate or alter results. A single researcher may be the only person who has been involved in the practical work of an experiment or who has collected all the trial data. Distant co-authors may not be in a position to question the main researcher or indeed may themselves be dazzled by the importance of the study 'findings'. Statisticians can use favorable statistical techniques or ignore parts of the data that are inconvenient, whilst authors of the final paper can 'accidentally' transpose figures or data.

- Stating the obvious

Some researchers may feel they know what the outcome of the research 'should be'. When the results do not come out as expected, they may consider it their duty to alter the results to those they are sure are 'correct'. Indeed, they may feel it is morally right to hide contrary results.

Each case of research fraud has its own unique features, but will contain at least one of these self-justifications. It may be that the researcher actually feels they have done nothing wrong and although aware of their specific crime feels it is for a greater overall good - the end justifying the means. 
But, like all falsehoods, research fraud is wrong and it is wrong for a number of reasons. Science and research are about discovering the truth (whatever that may be). If false findings are published then this truth is wrong but will be perceived as right. Ideally, all research findings should be replicated, but this does not always happen and the false finding may persist for some considerable time.

A false paper may be seen as giving a definitive answer to a scientific or clinical question, meaning that further research to replicate the findings will not be supported by funders or institutions. There have been examples where false research has sent scientists in the wrong direction in their future research and it is only years later that the original research was found to be fraudulent. ${ }^{1}$ False research can therefore cost huge amounts of time and money. ${ }^{1}$

Even more worrying, falsified clinical research especially arising from treatment trials - could be potentially harmful if inappropriate or ineffective treatments are pursued. ${ }^{2}$ If this occurs within a large multinational trial there may not be the resources available to repeat the trial. Lives can literally be put at stake by the movement of a decimal point or the alteration of a graph.

From a personal point of view, being unmasked as the perpetrator of research fraud can have very serious consequences. Loss of position, income, and reputation are a high price for an individual to pay, although necessary in order to deter others from following the same path. Sometimes criminal proceedings have been the result of an uncovered fraud. ${ }^{3}$

Research fraud undermines the trust of the public, funding bodies, journalists and politicians. ${ }^{4}$ This can have knock-on effects upon the vast majority of ethically conducted research, with a resulting lack of support for future work. No research should be accepted without a healthy dose of skepticism, but if fraud is thought to be widespread there is a danger that all research findings are ignored. A similar example is in professional cycling where at times there has been a public assumption that all competitors are using performance-enhancing substances. Who wants to watch a race that appears to be between cheats, and who wants to believe any scientific findings when you know some may be false?

There are a myriad of good reasons why research should not be falsified but perhaps, ultimately, the strongest reason comes from the very origins of scientific research itself. Sir Isaac Newton famously stated, "If I have seen further it is by standing on the shoulders of giants." Does any scientist or clinician really set out in their career not aspiring to be a giant?

The above reasons explain why research fraud is wrong. It is therefore logical that it should be prevented - but who should be responsible for this? The answer is that anyone involved in any of the steps, from the conception of the research to its final publication, has a responsibility. Be it co-authors, colleagues, supervisors, statisticians, peer reviewers, journal editors, ethics committees, research funders, or academic institutions: all must be on their guard for suspected fraud. Equally, they must have robust but fair mechanisms for investigating alleged fraud and dealing with it appropriately when proved.

Of course, it is inevitable that some determined individuals will get away with fraud no matter how effective the mechanisms to detect it. Like so many things in life, it then comes down to a matter of individual conscience and virtues. Let us hope our universities, medical schools, hospitals, and other academic institutions are fostering a culture of ethical research.

\section{References}

1. Michalek AM, Hutson AD, Wicher CP, Trump DL. The costs and underappreciated consequences of research misconduct: a case study. PLoS Med. 2010;7(8):e1000318.

2. Weijer $C$. The breast cancer research scandal: addressing the issues. CMAJ. 1995;152(8):1195-1197.

3. Clinical-Trial Fraud: The Case Of Ketek [webpage on the Internet]. Los Angeles: PharmaLive; 2007. Available from: http://www.pharmalive. com/clinical-trial-fraud-case-ketek. Accessed September 13, 2013.

4. Godlee F, Smith J, Marcovitch H. Wakefield's article linking MMR vaccine and autism was fraudulent. BMJ. 2011;342:c7452.
International Journal of General Medicine

\section{Publish your work in this journal}

The International Journal of General Medicine is an international, peer-reviewed open-access journal that focuses on general and internal medicine, pathogenesis, epidemiology, diagnosis, monitoring and treatment protocols. The journal is characterized by the rapid reporting of reviews, original research and clinical studies across all disease areas.
A key focus is the elucidation of disease processes and management protocols resulting in improved outcomes for the patient.The manuscript management system is completely online and includes a very quick and fair peer-review system. Visit http://www.dovepress.com/ testimonials.php to read real quotes from published authors. 